\title{
Effects of Nitric Oxide Donor on the Lung Functions in a Saline Lavage-Induced Model of ARDS
}

\author{
P. KOSUTOVA ${ }^{1,2}$, P. MIKOLKA ${ }^{1,2}$, S. BALENTOVA $^{3}$, M. ADAMKOV ${ }^{3}$, D. MOKRA MOL $^{1,2}$ \\ ${ }^{1}$ Biomedical Center Martin, Jessenius Faculty of Medicine in Martin, Comenius University in \\ Bratislava, Slovak Republic, ${ }^{2}$ Department of Physiology, Jessenius Faculty of Medicine in Martin, \\ Comenius University in Bratislava, Slovak Republic, ${ }^{3}$ Department of Histology and Embryology, \\ Jessenius Faculty of Medicine in Martin, Comenius University in Bratislava, Slovak Republic
}

Received March 22, 2019

Accepted October 27, 2019

\section{Summary}

Acute respiratory distress syndrome (ARDS) is characterized by acute hypoxemia, neutrophil-mediated inflammation, and lung edema formation. Whereas lung damage might be alleviated by nitric oxide (NO), goal of this study was to evaluate if intratracheal NO donor S-nitroso-N-acetylpenicillamine (SNAP) can positively influence the lung functions in experimental model of ARDS. New Zealand rabbits with respiratory failure induced by saline lavage (30 ml/kg, $9 \pm 3$ times) were divided into: ARDS group without therapy, ARDS group treated with SNAP $(7 \mathrm{mg} / \mathrm{kg}$ i.t.), and healthy Control group. During $5 \mathrm{~h}$ of ventilation, respiratory parameters (blood gases, ventilatory pressures) were estimated. After anesthetics overdosing, left lung was salinelavaged and cell count, cell viability and protein content in bronchoalveolar lavage fluid (BALF) were measured. Right lung tissue was used for estimation of wet/dry weight ratio, concentration of NO metabolites, and histomorphological investigation. Repetitive lung lavage induced lung injury, worsened gas exchange, and damaged alveolar-capillary membrane. Administration of SNAP reduced cell count in BALF, lung edema formation, NO metabolites, and histopathological signs of injury, and improved respiratory parameters. Treatment with intratracheal SNAP alleviated lung injury and edema and improved lung functions in a saline-lavaged model of ARDS suggesting a potential of NO donors also for patients with ARDS.

\section{Key words}

ARDS • Nitric oxide donor • SNAP • Lung injury • Saline lung lavage

\section{Corresponding author}

D. Mokra, Biomedical Center Martin and Department of Physiology, Jessenius Faculty of Medicine in Martin, Comenius University in Bratislava, Mala Hora 4C, SK-03601 Martin, Slovak Republic. E-mail: daniela.mokra@uniba.sk

\section{Introduction}

Acute respiratory distress syndrome (ARDS) is a life-threatening syndrome characterized by damage of alveolar-capillary membrane, hypoxemic respiratory failure, decreased dynamic lung compliance and bilateral radiographic infiltrates with no clinical evidence of cardiogenic pulmonary edema (Ranieri et al. 2012, Bellani et al. 2016).

Diffuse alveolar injury is linked with activation of lung macrophages which release numerous cytokines including interleukin (IL)-1 $\beta$, IL-6, IL-8, and tumor necrosis factor (TNF)- $\alpha$. These substances stimulate transmigration of additional polymorphonuclears (PMN), particularly of neutrophils, into the lung, and their activation. Activated neutrophils release huge concentrations of lipid mediators, proteases, and oxidants that continue to injure the lung and perpetuate the ARDS vicious cycle (Ware and Matthay 2000).

Nitric oxide (NO) is an important mediator in both physiological and pathological processes (Liaudet et al. 2000). NO is produced by conversion of L-arginine to L-citrulline, a reaction catalyzed by one of three NO synthases (NOS): neuronal (nNOS), endothelial (eNOS), and inducible (iNOS) (Phillips et al. 2009). 
NO participates in regulation of vascular tone, inhibition of platelet aggregation, attenuation of leukocyte adherence to the endothelium, scavenging of oxygenderived free radicals, maintenance of normal vascular permeability, inhibition of smooth muscle proliferation, immune defense, and stimulation of endothelial cell regeneration (Phillips et al. 2009). On the other hand, abundant production of NO and its metabolites (e.g. in inflammation) can be deleterious. NO reacts with superoxide anions to form a highly potent oxidant peroxynitrite which together with other oxidants damages proteins, lipids, and nucleic acids. The complex action of inflammatory processes and oxidative effects of reactive oxygen and nitrogen species (RONS) finally leads to a disruption of the alveolar-capillary barrier with subsequent formation of interstitial and alveolar edema and progression of lung injury (Lamb et al. 1999).

Despite improved understanding the pathophysiology of ARDS, decades of research have failed to find effective pharmacotherapies that can substantially reduce mortality in established ARDS (Yadav et al. 2017). Several studies have shown that administration of exogenous NO (i.e. inhaled NO or NO donor) can besides vasodilation and bronchodilation actions exert some anti-inflammatory effects, such as attenuation of leukocyte-endothelial cell adhesion, platelet-leukocyte aggregation, mast cell degranulation, production of inflammatory mediators, and modulation of vascular permeability (Fukuda et al. 1995, McKinley et al. 2000), and therefore, can be of benefit in inflammatory lung diseases, as well. For instance, inhaled NO attenuated pulmonary hypertension, enhanced gas exchange, and suppressed transendothelial migration of activated neutrophils and synthesis of pro-inflammatory cytokines in a model of septic acute lung injury (ALI) (Miao et al. 2002). S-nitroso-N-acetylpenicillamine (SNAP), an NO-releasing compound, has also shown prompt and several hours-lasting bronchodilation (Dupuy et al. 1992), pulmonary artery relaxation in hypoxemic conditions (Lakshminrusimha et al. 2013), and antiinflammatory effects in in vitro and in vivo lipopolysaccharide exposure (Lee et al. 2015). Because of these properties, we have expected that SNAP could be suitable also to alleviate the changes associated with ARDS. Our recently published results showed that intratracheal administration of S-nitroso-N-acetylpenicillamine (SNAP) influenced transmigration of neutrophils into the lung, decreased concentrations of markers of lung injury, oxidative stress, and inflammation, and reduced lung epithelial cell apoptosis (Kosutova et al. 2016a). In this article, additional results of the mentioned study are provided: effects of SNAP on gas exchange, respiratory parameters, histopathological signs of the lung injury, concentrations of NO metabolites in the lung tissue, and determination of lung edema formation using wet-dry (W/D) lung weight ratio and protein content in bronchoalveolar lavage fluid (BALF).

\section{Methods}

\section{General design of experiments}

Experimental protocols were performed in accordance with the ethical guidelines and authorized by the local Ethics Committee of Jessenius Faculty of Medicine in Martin, Comenius University in Bratislava and by National Veterinary Board.

In the study, adult New Zealand white rabbits of both genders and mean body weight (b.w.) of $3.0 \pm 0.3 \mathrm{~kg}$ were used. After anesthetic and surgical procedures described earlier (Kosutova et al. 2016a,b), $\mathrm{n}=6$ animals were overdosed by anesthetics and served as healthy nonventilated controls (Control group). Other animals were subjected to a pressure-controlled ventilator Beat-2 (Chirana, Slovakia) and ventilated with following settings: frequency (f) of $30 / \mathrm{min}$, fraction of inspired oxygen $\left(\mathrm{FiO}_{2}\right)$ of 1.0 , time of inspiration (Ti) $50 \%$, peak inspiratory pressure (PIP)/positive end-expiratory pressure (PEEP) $1.5 / 0.3 \mathrm{kPa}$ and tidal volume $\left(\mathrm{V}_{\mathrm{T}}\right)$ of $6-8 \mathrm{ml} / \mathrm{kg}$ b.w.). After $15 \mathrm{~min}$ of stabilization, respiratory parameters were measured and arterial blood gases were analyzed by analyzer RapidLab 348 (Siemens, Germany).

\section{Model of ARDS}

Lung injury was induced by repetitive saline lung lavage. Normal saline $(0.9 \% \mathrm{NaCl}, 30 \mathrm{ml} / \mathrm{kg}$ b.w., $37^{\circ} \mathrm{C}$ ) was instilled into the endotracheal tube in semiupright right and left lateral positions of the animal and was immediately suctioned by a suction device. The lavage procedure was performed 9-12 times, until $\mathrm{PaO}_{2}$ decreased to $<26.7 \mathrm{kPa}$ in $\mathrm{FiO}_{2} 1.0$ in 2 measurements at 5 and 15 min after the lavage. At this time point, ventilatory parameters and blood gases were recorded again.

\section{Therapy administration}

When the criteria of ARDS model were fullfilled, animals were treated with S-nitroso-N-acetyl-penicillamine (dose of $7 \mathrm{mg} / \mathrm{kg}$; ARDS+SNAP group, $\mathrm{n}=6$ ) which was 
given intratracheally by means of impulsion effect of highfrequency jet ventilation (f. 300/min, Ti $20 \%$; Mikolka et al. 2016, Kosutova et al. 2016a) to ensure homogenous distribution of SNAP throughout the lung, or animals were left without therapy (ARDS group, $n=6$ ). Animals were oxygen-ventilated $\left(\mathrm{FiO}_{2}\right.$ 1.0, frequency $30 / \mathrm{min}$, PIP/PEEP $1.5 / 0.3 \mathrm{kPa}, \mathrm{V}_{\mathrm{T}} 6-8 \mathrm{ml} / \mathrm{kg}$ b.w.) for an additional $5 \mathrm{~h}$ after the treatment administration. Blood gases, and respiratory parameters were measured at $30 \mathrm{~min}, 1,2,3,4$, and $5 \mathrm{~h}$ of the treatment. At the end of experiment, animals were overdosed by anesthetics.

Measurement of respiratory parameters and calculation of indexes of oxygenation

Tracheal airflow and $\mathrm{V}_{\mathrm{T}}$ were measured by a heated Fleisch head connected to a pneumotachograph. Airway pressure was registered via a pneumatic catheter placed in the tracheal tube and connected to electromanometer (Tesla, Czech Republic).

Mean airway pressure (MAP), oxygenation index (OI), ventilation efficiency index (VEI), $\mathrm{PaO}_{2} / \mathrm{FiO}_{2}$ ratio, Alveolar partial pressure of $\mathrm{O}_{2}\left(\mathrm{P}_{\mathrm{A}} \mathrm{O}_{2} \mathrm{~mm} \mathrm{Hg}\right)$ and alveolar-arterial (A-a) gradient were calculated as described earlier (Kosutova et al. 2017).

\section{Post mortem measurements}

After killing the animal, lungs and trachea were excised. Left lung was 3-times lavaged by saline $(0.9 \%$ $\mathrm{NaCl}, 10 \mathrm{ml} / \mathrm{kg}$ b.w.) and BALF was used for analysis of cells and protein content (see below). Right lung tissue was used for estimation of W/D ratio, analysis of NO metabolites, and histological investigation.

\section{Analysis of cells and total protein content in BALF}

Viability and total number of cells in BALF were determined by cell analyzer Countess (Invitrogen, USA). Total protein in BALF was measured by methods of Bradford (1976), as published by us earlier (Kosutova et al. 2018).

\section{W/D ratio}

Strip of right lung tissue was weighed and dried in an incubator at $65^{\circ} \mathrm{C}$ for $48 \mathrm{~h}$. Then, the dry weight was determined and $\mathrm{W} / \mathrm{D}$ ratio calculated.

Measurement of NO metabolites (concentration of nitrite/nitrate, $N O x$ )

Lung tissue homogenate was prepared as published earlier (Kosutova et al. 2016a). Concentrations of NOx were determined using Cayman's Nitrate/Nitrite Colorimetric Assay Kit (Alexis Corp., San Diego, CA), according to the manufacturer's instruction. The results were analyzed spectrophotometrically at $540 \mathrm{~nm}$ using an ELISA microplate reader.

\section{Histopathological investigation of the lung tissue}

The lung tissue injury was evaluated and the Lung Injury Score (LIS) was calculated as described previously (Mokra et al. 2016). The lung sample was fixed in $4 \%$ paraformaldehyde, dehydrated, embedded in paraffin, sectioned (thickness of $4 \mu \mathrm{m}$ ), and stained with hematoxylin. To score lung injury and inflammation, lung tissue samples were screened for following histopathological signs: 1) atelectasis, 2) emphysema, 3) hemorrhagia, and 4) PMN infiltration. Samples were evaluated by an experienced histopathologist blinded to the grouping of animals, and results were scored of 0-3 with 0 as absent (normal), 1 as mild, 2 as moderate, and 3 as severe lung injury. The total value of TIS was calculated as a sum of these scores.

\section{Statistical analysis}

Statistical analysis was performed by GraphPad Prism version 6.01 for Windows (GraphPad Software, USA). Data are presented as means \pm SEM and differences between the groups were determined by analysis of variance (ANOVA) and Kruskal-Wallis test. Within-group differences were evaluated by Wilcoxon test. A value of $\mathrm{P}<0.05$ was considered significant.

\section{Results}

Body weights of animals and initial values of the parameters before induction of the ARDS model were comparable between the groups (all $\mathrm{P}>0.05$ ).

\section{Respiratory parameters}

After induction of ARDS model, values of VEI decreased in ARDS group to $37 \%$ and in ARDS+SNAP group to $42 \%$ of the initial values (both $\mathrm{P}<0.001$; Fig. 1 ). Reduced ventilation efficiency resulted in worsened oxygenation and oxygen saturation of hemoglobin compared to values before induction of ARDS (all $\mathrm{P}<0.05$; Table 1). After induction of lung injury in ARDS group and ARDS+SNAP group, $\mathrm{PaO}_{2} / \mathrm{FiO}_{2}$ decreased to $13-17 \%$ of the initial values, OI increased 7-9 times (all $\mathrm{P}<0.001$ versus initial values). SNAP therapy decreased $\mathrm{OI}$ by $46 \%$ at $30 \mathrm{~min}$ after the 
treatment compared to the OI value after induction of ARDS model, and by $56-57 \%$ at $1-4 \mathrm{~h}$, and $24 \%$ at $5 \mathrm{~h}$. After induction of lung injury, significant differences between ARDS+SNAP group and ARDS group in OI were found at $30 \mathrm{~min}(\mathrm{P}<0.01)$, and at $1-5 \mathrm{~h}(\mathrm{P}<0.01$ or 0.001 ), after the treatment delivery (Fig. 1A).

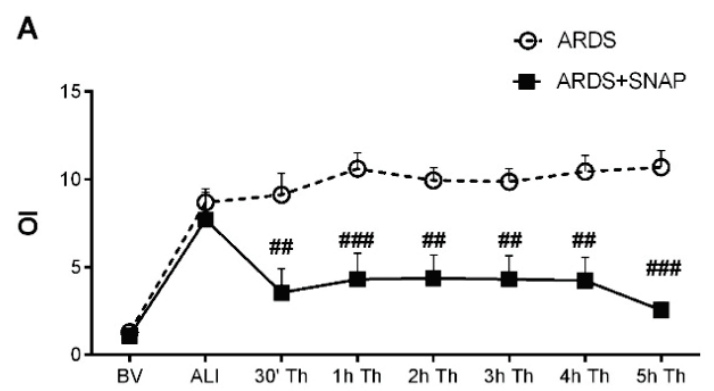

B
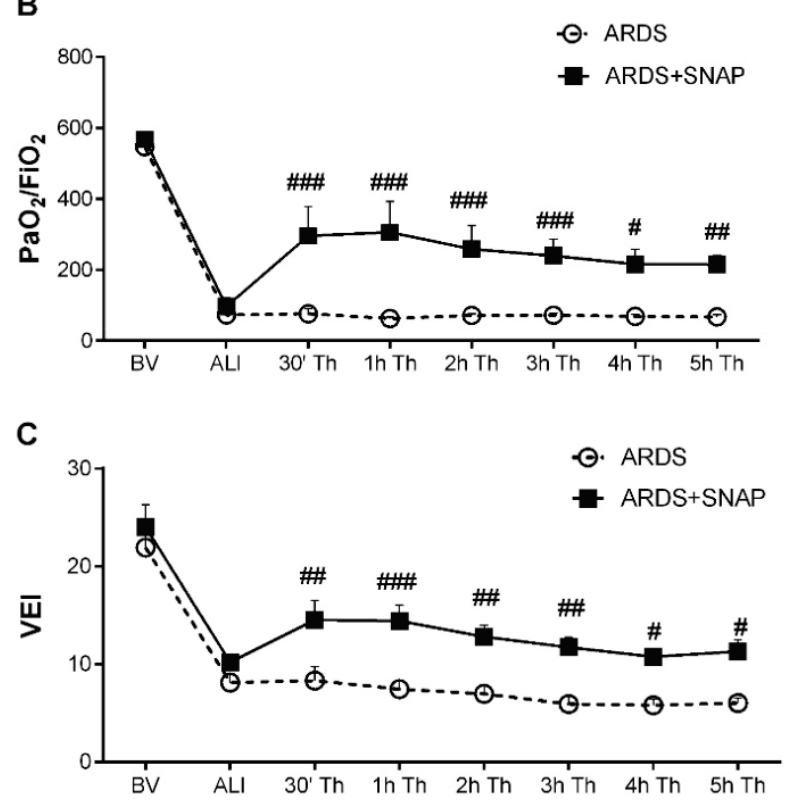

Fig. 1. The ratio of arterial oxygen partial pressure to fraction of inspired oxygen oxygenation index (OI) (A); $\mathrm{PaO}_{2} / \mathrm{FiO}_{2}$ (in $\mathrm{kPa}$ ) (B), and ventilation efficiency index (VEI) (C) before (basal value, BV) and after elicitation of acute respiratory distress syndrome (ARDS) and within $5 \mathrm{~h}$ after administration of the therapy (Th) in non-treated animals with ARDS (ARDS group) and in animals with ARDS treated with SNAP (ARDS+SNAP group). Statistical comparisons: ARDS+SNAP vs. ARDS \# $\mathrm{P}<0.05$, ${ }^{\# \#} \mathrm{P}<0.01,{ }^{\# \# \#} \mathrm{P}<0.001$. Data are presented as means $\pm \mathrm{SEM}$.

SNAP therapy caused a 3-fold increase in $\mathrm{PaO}_{2} / \mathrm{FiO}_{2}$ at $30 \mathrm{~min}$ after the treatment compared to $\mathrm{PaO}_{2} / \mathrm{FiO}_{2}$ value after induction of lung injury, and this improvement was observed till the end of experiment. After induction of lung injury, significant differences between ARDS+SNAP group and ARDS group in $\mathrm{PaO}_{2} / \mathrm{FiO}_{2}$ were found at $30 \mathrm{~min}-3 \mathrm{~h}(\mathrm{P}<0.001)$, at $4 \mathrm{~h}$ $(\mathrm{P}<0.05)$, and at $5 \mathrm{~h}(\mathrm{P}<0.01)$ after the treatment delivery (Fig. 1B).
SNAP therapy increased VEI by $39 \%$ at $30 \mathrm{~min}$ after the treatment compared to the VEI value after induction of lung injury, and by $41 \%$ at $1 \mathrm{~h}, 25 \%$ at $2 \mathrm{~h}$ and $14 \%$ at $3 \mathrm{~h}$, and this effect declined to $5-10 \%$ at 4-5 h. After induction of lung injury, significant differences between ARDS+SNAP group and ARDS group in VEI were found since $30 \mathrm{~min}$ after the treatment delivery $(\mathrm{P}<0.05,0.01$ or 0.001 , Fig. $1 \mathrm{C})$.

Other respiratory parameters (MAP, $\mathrm{PaCO}_{2}, \mathrm{pH}$, $\mathrm{PaO}_{2}, \mathrm{AAG}, \mathrm{SatO}_{2}$ ) had been also severely altered after the ARDS model elicitation compared to baseline values (time sequence ARDS vs. basal value, $\mathrm{BV}$; all $\mathrm{P}<0.01$ ). SNAP administration significantly improved $\mathrm{PaO}_{2}$, MAP $(\mathrm{P}<0.001)$, and AAG $(\mathrm{P}<0.01)$ from $30 \mathrm{~min}$ and $\mathrm{PaCO}_{2}$ from $2 \mathrm{~h}(\mathrm{P}<0.05$, Table 1$)$.

\section{Analysis of cells in BALF}

Repetitive lung lavage significantly elevated a total number of cells ( $\mathrm{P}<0.001$ for ARDS vs. Control) and viability $(\mathrm{P}<0.01$ for ARDS vs. Control) in BALF compared to controls, while SNAP therapy inhibited the infiltration of cells into the lungs $(\mathrm{P}<0.01$ for ARDS+SNAP vs. ARDS), without significant difference in cell viability (Fig. 2A, B).

\section{Lung edema formation}

Formation of the lung edema expressed as wetdry lung weight ratio (W/D ratio) increased in ARDS animals compared to controls $(\mathrm{P}<0.001)$, while administration of SNAP decreased the $\mathrm{W} / \mathrm{D}$ ratio (ARDS+SNAP vs. ARDS, $\mathrm{P}<0.05$ ) (Fig. 2C).

Similarly, protein level in BALF was higher in ARDS animals compared to healthy controls, what underlined deterioration of alveolar-capillary membrane and leaking fluid into alveolar space (ARDS vs. Control, $\mathrm{P}<0.001)$. Treatment with SNAP decreased protein concentration in BALF compared to untreated animals (ARDS+SNAP vs. ARDS, $\mathrm{P}<0.05$ ) (Fig. 2D).

\section{Concentration of nitrite/nitrate (NOx) in the lung tissue}

Nitrite/nitrate concentration in the lung tissue was significantly higher in the ARDS group compared with controls $(\mathrm{P}<0.001)$ and decreased in the ARDS+SNAP group compared with the untreated ARDS group ( $\mathrm{P}<0.01$; Fig. $2 \mathrm{E}$ ). Similarly, nitrite concentration was significantly higher in the ARDS group compared with controls $(\mathrm{P}<0.01)$ and decreased in the ARDS+SNAP group compared with the untreated ARDS group $(\mathrm{P}<0.05$; Fig. $2 \mathrm{~F})$. 
Table 1. Mean airway pressure (MAP), arterial partial pressure of carbon dioxide $\left(\mathrm{PaCO}_{2}\right)$, arterial $\mathrm{pH}$, arterial oxygen saturation $\left(\mathrm{SatO}_{2}\right)$, arterial partial pressure of oxygen $\left(\mathrm{PaO}_{2}\right)$ and alveolar-arterial gradient (AAG) before (basal value, BV) and after elicitation of acute respiratory distress syndrome (ARDS) and within $5 \mathrm{~h}$ after administration of therapy (Th) in non-treated animals with ARDS (ARDS group) and in animals with ARDS treated with SNAP (ARDS+SNAP group). Statistical comparisons: for ARDS+SNAP vs. ARDS ${ }^{\#} \mathrm{P}<0.05,{ }^{\# \#} \mathrm{P}<0.01,{ }^{\# \# \#} \mathrm{P}<0.001$. Data are presented as means $\pm \mathrm{SEM}$.

\begin{tabular}{|c|c|c|c|c|c|c|c|c|}
\hline & BV & ALI & $30^{\prime} \mathrm{Th}$ & $1 \mathrm{~h} \mathrm{Th}$ & $2 \mathrm{~h} \mathrm{Th}$ & 3 h Th & $4 \mathrm{~h} \mathrm{Th}$ & $5 \mathrm{~h} \mathrm{Th}$ \\
\hline \multicolumn{9}{|l|}{$\boldsymbol{M A P}(k P a)$} \\
\hline$A R D S$ & $0.9 \pm 0.0$ & $0.9 \pm 0.0$ & $0.9 \pm 0.0$ & $0.9 \pm 0.0$ & $0.9 \pm 0.0$ & $0.9 \pm 0.0$ & $0.9 \pm 0.0$ & $0.9 \pm 0.0$ \\
\hline$A R D S+S N A P$ & $0.8 \pm 0.0$ & $0.8 \pm 0.0$ & $0.8 \pm 0.0^{\# \# \#}$ & $0.7 \pm 0.0^{\# \#}$ & $0.7 \pm 0.0^{\# \# \#}$ & $0.7 \pm 0.0^{\# \# \#}$ & $0.7 \pm 0.0^{\# \#}$ & $0.7 \pm 0.0^{\# \#}$ \\
\hline \multicolumn{9}{|l|}{$\mathrm{PaCO}_{2}(\mathrm{kPa})$} \\
\hline$A R D S$ & $3.0 \pm 0.2$ & $7.6 \pm 0.7$ & $7.4 \pm 0.8$ & $8.7 \pm 0.8$ & $9.1 \pm 1.2$ & $10.5 \pm 1.5$ & $10.6 \pm 1.5$ & $10.9 \pm 1.7$ \\
\hline$A R D S+S N A P$ & $2.4 \pm 0.3$ & $5.7 \pm 0.3$ & $4.2 \pm 0.6$ & $4.1 \pm 0.5$ & $4.6 \pm 0.5^{\#}$ & $4.9 \pm 0.4^{\# \#}$ & $5.3 \pm 0.4^{\#}$ & $5.7 \pm 0.8^{\#}$ \\
\hline \multicolumn{9}{|l|}{$p H$} \\
\hline$A R D S$ & $7.6 \pm 0.0$ & $7.2 \pm 0.0$ & $7.2 \pm 0.0$ & $7.2 \pm 0.0$ & $7.1 \pm 0.0$ & $7.1 \pm 0.0$ & $7.1 \pm 0.0$ & $7.1 \pm 0.0$ \\
\hline$A R D S+S N A P$ & $7.6 \pm 0.0$ & $7.3 \pm 0.0$ & $7.3 \pm 0.01$ & $7.2 \pm 0.1$ & $7.1 \pm 0.0$ & $7.1 \pm 0.0$ & $7.1 \pm 0.0$ & $7.0 \pm 0.0$ \\
\hline \multicolumn{9}{|l|}{$\mathrm{SatO}_{2}$} \\
\hline$A R D S$ & $99.9 \pm 0.0$ & $94.4 \pm 1.0$ & $97.4 \pm 0.4$ & $97.4 \pm 1.2$ & $96.5 \pm 1.3$ & $96.4 \pm 1.3$ & $95.2 \pm 2.2$ & $95.0 \pm 2.4$ \\
\hline$A R D S+S N A P$ & $99.9 \pm 0.0$ & $97.8 \pm 1.1$ & $98.3 \pm 1.2$ & $98.6 \pm 1.0$ & $97.2 \pm 2.1$ & $98.3 \pm 0.8$ & $98.5 \pm 0.7$ & $98.7 \pm 0.5$ \\
\hline \multicolumn{9}{|l|}{$\mathrm{PaO}_{2}(k \mathrm{~Pa})$} \\
\hline$A R D S$ & $72.9 \pm 2.2$ & $10.9 \pm 0.9$ & $11.4 \pm 1.6$ & $9.0 \pm 0.8$ & $9.5 \pm 0.7$ & $9.6 \pm 0.8$ & $9.1 \pm 0.8$ & $8.9 \pm 0.8$ \\
\hline$A R D S+S N A P$ & $75.8 \pm 2.6$ & $12.9 \pm 3.2$ & $39.4 \pm 11.0^{\# \#}$ & $40.8 \pm 11.5^{\# \# \#}$ & $34.5 \pm 8.9^{\# \# \#}$ & $31.9 \pm 6.3^{\# \# \#}$ & $28.7 \pm 5.5^{\#}$ & $28.6 \pm 3.4^{\#}$ \\
\hline \multicolumn{9}{|l|}{$A A G$} \\
\hline$A R D S$ & $125.0 \pm 11.9$ & $572.8 \pm 3.2$ & $559.8 \pm 7.9$ & $541.2 \pm 19.8$ & $556.1 \pm 8.9$ & $535.2 \pm 10.9$ & $548.0 \pm 4.5$ & $548.0 \pm 5.3$ \\
\hline$A R D S+S N A P$ & $122.5 \pm 21.4$ & $535.9 \pm 34.3$ & $417.8 .0 \pm 85.1^{\# \#}$ & $366.8 \pm 81.7^{\# \# \#}$ & $373.1 \pm 66.8^{\mathrm{\# \#}}$ & $359.3 \pm 24.9^{\# \#}$ & $416.1 \pm 38.3$ & $444.4 \pm 22.3$ \\
\hline
\end{tabular}

A

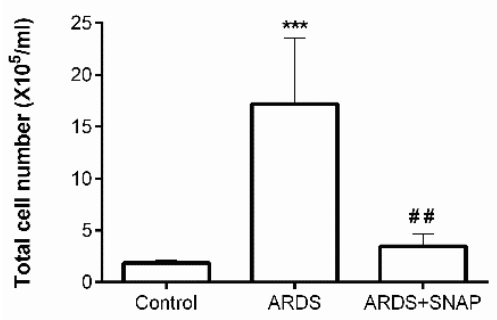

D

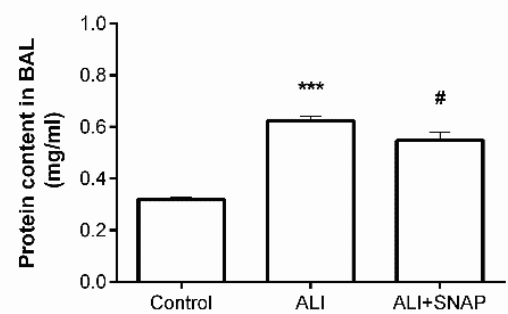

B

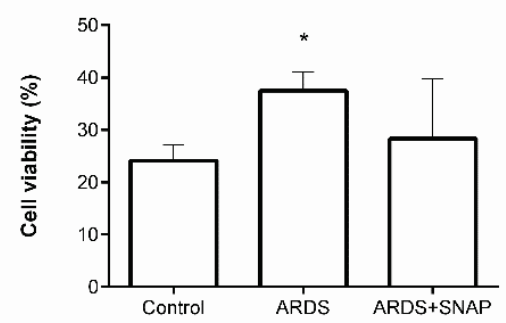

$\mathbf{E}$

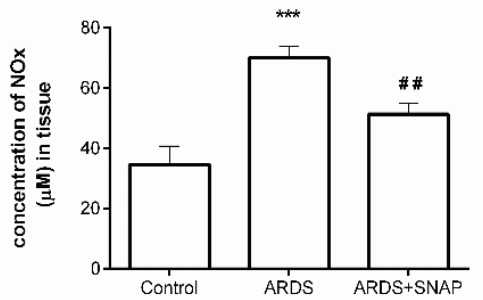

\section{C}

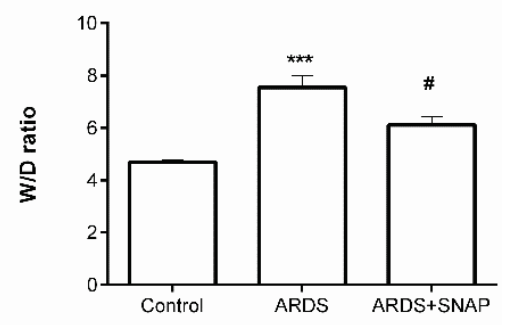

$\mathbf{F}$

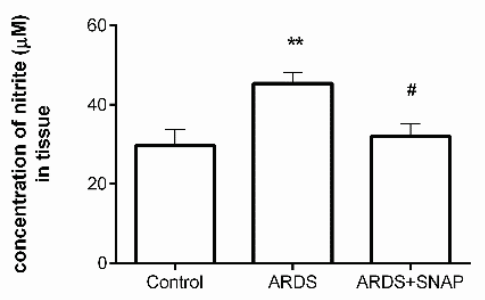

Fig. 2. Total number of cells in BALF (A), viability of cells in BALF (B), lung edema formation expressed as wet-dry (W/D) lung weight ratio $(\mathbf{C})$ and protein content in $\operatorname{BALF}(\mathrm{mg} / \mathrm{ml})(\mathbf{D})$, concentration of nitrite/nitrate in lung tissue $(\mu \mathrm{M})(\mathbf{E})$, concentration of nitrite in lung tissue $(\mu \mathrm{M})(\mathbf{F})$, in healthy non-ventilated animals (Control group), in non-treated animals with ARDS (ARDS group) and in animals with ARDS treated with SNAP (ARDS+SNAP group). Statistical comparisons: for ARDS vs. Control ${ }^{*} \mathrm{P}<0.05,{ }^{* *} \mathrm{P}<0.01,{ }^{* * *} \mathrm{P}<0.001$; ARDS+SNAP vs. ARDS ${ }^{\#} \mathrm{P}<0.05,{ }^{\# \#} \mathrm{P}<0.01$. Data are presented as means $\pm \mathrm{SEM}$.

\section{Lung histology}

Histological investigation using hematoxylineosin staining showed higher occurrence of atelectasis (for ARDS vs. Control, $\mathrm{P}<0.01$ ), emphysema (for ARDS vs. Control, $\mathrm{P}<0.05)$, hemorrhage, as well as increased neutrophil sequestration in the lung (for ARDS vs. Control, $\mathrm{P}<0.001$ ), and total injury score (TIS) (for ARDS vs. Control, $\mathrm{P}<0.01)$. In SNAP-treated animals, the lung injury was significantly reduced (for atelectasis $\mathrm{P}<0.01$, for emphysema $\mathrm{P}<0.05$ and for TIS $\mathrm{P}<0.05$; Table 2 ). 
Table 2. Histopathological signs (expressed as a score) in the lungs of healthy controls (Control group), in the non-treated ARDS group (ARDS group) and in the animals with ARDS treated with SNAP (ARDS+SNAP group). Statistical comparisons: for ARDS vs. Control ${ }^{*} \mathrm{P}<0.05,{ }^{* *} \mathrm{P}<0.01,{ }^{* * *} \mathrm{P}<0.001$, for ARDS+SNAP vs. ARDS ${ }^{\#} \mathrm{P}<0.05,{ }^{\# \#} \mathrm{P}<0.01$. Data are presented as means \pm SEM.

\begin{tabular}{lccc}
\hline & Control & ARDS & ARDS+SNAP \\
\hline Atelectasis & $0.4 \pm 0.2$ & $2.6 \pm 0.2^{* *}$ & $1.2 \pm 0.5^{\# \#}$ \\
Emphysema & $0.4 \pm 0.2$ & $2.0 \pm 0.4^{*}$ & $1.0 \pm 0.3^{\#}$ \\
Hemorrhagia & $0.4 \pm 0.2$ & $1.8 \pm 0.6$ & $0.5 \pm 0.3$ \\
PMN infiltration & $0.6 \pm 0.2$ & $2.4 \pm 0.2^{* * *}$ & $1.8 \pm 0.2$ \\
Total injury score (TIS) & $1.8 \pm 0.9$ & $7.4 \pm 0.9^{* *}$ & $4.2 \pm 1^{\#}$ \\
\hline
\end{tabular}

\section{Discussion}

Saline lung lavage in the present study induced severe changes in the respiratory parameters, elevated levels of NOx metabolites, increased permeability of alveolar-capillary membrane, and worsened histopathological signs of the lung injury (atelectasis, emphysema, hemorrhagia, PMN infiltration). Intratracheal administration of $7 \mathrm{mg} / \mathrm{kg}$ b.w. of SNAP improved gas exchange and other respiratory parameters, reduced transmigration of cells into the lung, reduced formation of lung edema and decreased levels of NOx metabolites in the lung, and improved histological findings.

ARDS may arise from a primary lung disease or secondary due to serious systemic disorders (Jain and McNamara 2015). Diffuse alveolar damage causes ventilation-perfusion mismatch and maldistribution of blood flow in the injured lung due to decreased lung compliance and increased intrapulmonary right-to-left shunting, leading to pulmonary hypertension and hypoxemia (Kaisers et al. 2003, Bellani et al. 2016).

In saline-lavaged rabbits in this study, arterial blood gas analysis showed obvious and stable decrease in arterial $\mathrm{PaO}_{2}$ with normal or increased $\mathrm{PaCO}_{2}$. The values of $\mathrm{PaO}_{2}$ remained below $15 \mathrm{kPa}$ in $\mathrm{FiO}_{2} 1.0$ and index of blood oxygenation $\left(\mathrm{PaO}_{2} / \mathrm{FiO}_{2}\right)$ below $200 \mathrm{~mm} \mathrm{Hg}$ what indicates that the model is suitable to mimic the changes related to the lung damage and correlates well with the clinical criteria of ARDS in patients. Our data are consistent with findings of earlier studies, which used the saline lavage-induced surfactant-depleted ARDS model (Ronchi et al. 2012, Fioretto et al. 2012).

Therapeutic interventions that can induce selective vasodilation in the pulmonary vasculature can result in decreased pulmonary artery pressure and rightto-left shunting what can finally increase $\mathrm{PaO}_{2} / \mathrm{FiO}_{2}$. Inhaled NO can selectively dilate blood vessels in only those lung segments that are actively participating in gas exchange at the alveolar-capillary level (Jain and McNamara 2015). Inhaled NO alleviated pulmonary hypertension, improved gas exchange and reduced inflammation and histopathological injury score in salinelavage model (Fioretto et al. 2012) and sepsis-induced model of ARDS (Miao et al. 2002). Improved ventilation/perfusion mismatch was also seen in patients with ARDS (Dellinger et al. 1998). In our study, intratracheal administration of soluble NO donor SNAP significantly improved respiratory parameters compared to non-treated animals with ARDS, whereas the changes become significant already within $30 \mathrm{~min}$ after SNAP administration.

Shortly after an initial insult, increased vascular permeability, alveolar flooding with protein-rich fluid, alveolar hemorrhage, and massive neutrophil infiltration may be detected ( $\mathrm{Lu}$ et al. 2005, Matthay and Zemans 2011). Activated cells in the lung produce various potentially noxious substances which cause inflammatory and oxidative/nitrosative changes and facilitate apoptosis of the lung epithelial cells. Cytokines/chemokines secreted by macrophages and PMN, such as IL-1 $\beta$, IL-8, and TNF- $\alpha$, stimulate further transmigration of neutrophils, amplify the inflammatory cascade, and aggravate lung injury (Bhatia et al. 2012, Huang et al. 2016). Activated inflammatory cells also produce excessive concentrations of RONS, myeloperoxidase, proteases etc., which exacerbate capillary permeability and hemorrhage, and extend the time of neutrophil sequestration (Carnesecchi et al. 2012). Our recently published results showed lung lavage-induced migration of neutrophils into the alveolar space and their activation, as it was verified by finding of increased concentrations of pro-inflammatory cytokines, markers of epithelial and endothelial injury, expression of iNOS in the lung, concentrations of NO metabolites in the plasma, and 
higher extent of lung cell apoptosis. SNAP administration alleviated migration of the inflammatory cells, reduced markers of inflammation and oxidation, and decreased apoptosis of the lung cells (Kosutova et al. 2016). In this part of the study, dysfunction of the alveolar-capillary barrier and transendothelial diapedesis of leukocytes into the lung tissue were verified by additional methods. Cell analysis by analyzer Countess using Trypan blue confirmed significantly higher number of cells observed in BALF already $5 \mathrm{~h}$ after induction of ARDS.

Deterioration of alveolar-capillary barrier resulted into altered pulmonary capillary permeability which is related to impairment of epithelial tight junction, alveolar fluid clearance mechanisms, and surfactant production. Increased leak of protein through injured alveolar-capillary membrane was confirmed by finding of significantly higher total protein content in the BALF fluid measured by methods of Bradford. Similarly, higher edema formation was proven by higher W/D ratio in ARDS animals vs. controls. Treatment with SNAP significantly reduced protein concentration in BALF and W/D ratio, suggesting that SNAP protects the integrity of the alveolar-capillary membrane. These effects can be attributed to involvement of $\mathrm{NO}$ in protection from oxidative injury, in regulation of both immune and inflammatory responses, in modulation of neutrophil sequestration into the lung, and in modulation of edema formation (Prodhan and Noviski 2004).

Repetitive saline lung lavage used for elicitation of ARDS model in this study caused serious histopathological changes in the lung tissue. Particularly the morphological changes of epithelial cells type I can disturb the removal of fluid from the alveolar space and increase the risk of development of septic shock (Galani et al. 2010). In this study, histological investigation of the lung tissue samples taken at the end of experiments showed an increase in atelectasis, emphysema, hemorrhagia, and PMN infiltration in the lungs of animals with ARDS compared to controls. In agreement to our results, histopathological changes in the lung within several hours after induction of ARDS were observed also by other authors (Wang et al. 2006, Takano et al. 2011, Fioretto et al. 2012, Kamiyama et al. 2014). Some of these changes were significantly alleviated by administration of SNAP indicating that soluble NO donors may protect the ARDS lung from further injury.

In conclusion, intratracheal delivery of soluble NO donor SNAP significantly improved respiratory parameters and mitigated markers of lung injury and edema formation in a saline-lavaged rabbit model of ARDS. These favorable results may suggest a future potential of soluble NO donors administration also in patients with ARDS.

\section{Conflict of Interest}

There is no conflict of interest.

\section{Acknowledgements}

Authors thank D. Kuliskova, Z. Remisova, M. Petraskova, and M. Hutko for technical assistance. In addition, we would like to thank for support to projects APVV-15-0075, VEGA 1/0356/18, Biomedical Center Martin (ITMS 26220220187) and Center of Excellency in Perinatology II (CEPV II, ITMS 26220120016).

\section{References}

BELLANI G, LAFFEY JG, PHAM T, FAN E, BROCHARD L, ESTEBAN A, GATTINONI L, VAN HAREN F, LARSSON A, MCAULEY DF, RANIERI M, RUBENFELD G, THOMPSON BT, WRIGGE H, SLUTSKY AS, PESENTI A; LUNG SAFE Investigators; ESICM Trials Group. Epidemiology, Patterns of Care, and Mortality for Patients With Acute Respiratory Distress Syndrome in Intensive Care Units in 50 Countries. JAMA 315: 788-800, 2016. Erratum in: JAMA 316: 350, 2016.

BHATIA M, ZEMANS RL, JEYASEELAN S: Role of chemokines in the pathogenesis of acute lung injury. Am J Respir Cell Mol Biol 46: 566-572, 2012.

BRADFORD MM: A rapid and sensitive method for the quantitation of microgram quantities of protein utilizing the principle of protein-dye binding. Anal Biochem 72: 248-254, 1976.

CARNESECCHI S, PACHE JC, BARAZZONE-ARGIROFFO C: NOX enzymes: potential target for the treatment of acute lung injury. Cell Mol Life Sci 69: 2373-2385, 2012.

DELLINGER RP, ZIMMERMAN JL, TAYLOR RW, STRAUBE RC, HAUSER DL, CRINER GJ, DAVIS K JR, HYERS TM, PAPADAKOS P: Effects of inhaled nitric oxide in patients with acute respiratory distress syndrome: results of a randomized phase II trial. Inhaled Nitric Oxide in ARDS Study Group. Crit Care Med 26: $15-23,1998$. 
DUPUY PM, SHORE SA, DRAZEN JM, FROSTELL C, HILL WA, ZAPOL WM: Bronchodilator action of inhaled nitric oxide in guinea pigs. J Clin Invest 90: 421-428, 1992.

FIORETTO JR, CAMPOS FJ, RONCHI CF, FERREIRA AL, KUROKAWA CS, CARPI MF, MORAES MA, BONATTO RC, DEFAVERI J, YEUM KJ: Effects of inhaled nitric oxide on oxidative stress and histopathological and inflammatory lung injury in a saline-lavaged rabbit model of acute lung injury. Respir Care 57: 273-281, 2012.

FUKUDA H, SAWA Y, KADOBA K, TANIGUCHI K, SHIMAZAKI Y, MATSUDA H: Supplement of nitric oxide attenuates neutrophil-mediated reperfusion injury. Circulation 92: II413-II416, 1995.

GALANI V, TATSAKI E, BAI M, KITSOULIS P, LEKKA M, NAKOS G, KANAVAROS P: The role of apoptosis in the pathophysiology of Acute Respiratory Distress Syndrome (ARDS): an up-to-date cell-specific review. Pathol Res Pract 206: 145-150, 2010.

HUANG D, ZHAO Q, LIU H, GUO Y, XU H: PPAR- $\alpha$ Agonist WY-14643 Inhibits LPS-induced inflammation in synovial fibroblasts via NF-kB pathway. J Mol Neurosci 59: 544-553, 2016.

JAIN A, MCNAMARA PJ: Persistent pulmonary hypertension of the newborn: Advances in diagnosis and treatment. Semin Fetal Neonatal Med 20: 262-271, 2015.

KAISERS U, BUSCH T, DEJA M, DONAUBAUER B, FALKE KJ: Selective pulmonary vasodilation in acute respiratory distress syndrome. Crit Care Med 31: S337-S342, 2003.

KAMIYAMA J, JESMIN S, SAKURAMOTO H, SHIMOJO N, ISLAM MM, KHATUN T, OKI M, KAWANO S, MIZUTANI T: Assessment of circulatory and pulmonary endothelin-1 levels in a lavage-induced surfactantdepleted lung injury rabbit model with repeated open endotracheal suctioning and hyperinflation. Life Sci 118: 370-378, 2014.

KOSUTOVA P, MIKOLKA P, KOLOMAZNIK M, BALENTOVA S, CALKOVSKA A, MOKRA D: Effects of S-Nitroso-N-Acetyl-Penicillamine (SNAP) on inflammation, lung tissue apoptosis and iNOS activity in a rabbit model of acute lung injury. Adv Exp Med Biol 935: 13-23, 2016 a.

KOSUTOVA P, MIKOLKA P, BALENTOVA S, ADAMKOV M, KOLOMAZNIK M, CALKOVSKA A, MOKRA D: Intravenous dexamethasone attenuated inflammation and influenced apoptosis of lung cells in an experimental model of acute lung injury. Physiol Res 65 (Suppl 5): S663-S672, $2016 \mathrm{~b}$.

KOSUTOVA P, MIKOLKA P, KOLOMAZNIK M, REZAKOVA S, CALKOVSKA A, MOKRA D: Effects of roflumilast, a phosphodiesterase-4 inhibitor, on the lung functions in a saline lavage-induced model of acute lung injury. Physiol Res 66 (Suppl 2): S237-S245, 2017.

KOSUTOVA P, MIKOLKA P, KOLOMAZNIK M, BALENTOVA S, ADAMKOV M, CALKOVSKA A, MOKRA D: Reduction of lung inflammation, oxidative stress and apoptosis by the PDE4 inhibitor roflumilast in experimental model of acute lung injury. Physiol Res 67 (Suppl 4): S645-S654, 2018.

LAKSHMINRUSIMHA S, SURESH MV, KNIGHT PR, GUGINO SF, DAVIDSON BA, HELINSKI JD, NIELSEN LC, RUSSELL JA, YU B, ZENG L, PENNATHUR S, RAGHAVENDRAN K: Role of pulmonary artery reactivity and nitric oxide in injury and inflammation following lung contusion. Shock 39: 278-285, 2013.

LAMB NJ, QUINLAN GJ, WESTERMAN ST, GUTTERIDGE JM, EVANS TW: Nitration of proteins in bronchoalveolar lavage fluid from patients with acute respiratory distress syndrome receiving inhaled nitric oxide. Am J Respir Crit Care Med 160: 1031-1034, 1999.

LEE MY, SUN KH, CHIANG CP, HUANG CF, SUN GH, TSOU YC, LIU HY, TANG SJ: Nitric oxide suppresses LPS-induced inflammation in a mouse asthma model by attenuating the interaction of IKK and Hsp90. Exp Biol Med (Maywood) 240: 498-507, 2015.

LIAUDET L, SORIANO FG, SZABO C: Biology of nitric oxide signaling. Crit Care Med 28: N37-N52, 2000.

LU MP, DU LZ, GU WZ, CHEN XX: Nitric oxide inhalation inhibits inducible nitric oxide synthase but not nitrotyrosine formation and cell apoptosis in rat lungs with meconium-induced injury. Acta Pharmacol Sin 26: 1123-1129, 2005.

MATTHAY MA, ZEMANS RL: The acute respiratory distress syndrome: pathogenesis and treatment. Annu Rev Pathol 6: 147-163, 2011.

MCKINLEY BA, MARVIN RG, COCANOUR CS, POUSMAN RM, WARE DN, MOORE FA: Nitroprusside in resuscitation of major torso trauma. J Trauma 49: 1089-1095, 2000. Erratum in: J Trauma 50: 1162, 2001. 
MIAO CH, SUN B, JIANG H, XUE ZG, LINDWALL R: Pharmacodynamics and pharmacokinetics of inhaled nitric oxide in dogs with septic acute respiratory distress syndrome. Acta Pharmacol Sin 23: 278-284, 2002.

MOKRA D, KOSUTOVA P, BALENTOVA S, ADAMKOV M, MIKOLKA P, MOKRY J, ANTOSOVA M, CALKOVSKA A: Effects of budesonide on the lung functions, inflammation and apoptosis in a saline-lavage model of acute lung injury. $J$ Physiol Pharmacol 67: 919-932, 2016.

MIKOLKA P, KOPINCOVÁ J, KOŠÚTOVÁ P, ČIERNY D, ČALKOVSKÁ A, MOKRÁ D: Lung inflammatory and oxidative alterations after exogenous surfactant therapy fortified with budesonide in rabbit model of meconium aspiration syndrome. Physiol Res 65 (Suppl 5): S653-S662, 2016.

PHILLIPS L, TOLEDO AH, LOPEZ-NEBLINA F, ANAYA-PRADO R, TOLEDO-PEREYRA LH: Nitric oxide mechanism of protection in ischemia and reperfusion injury. J Invest Surg 22: 46-55, 2009.

PRODHAN P, NOVISKI N: Pediatric acute hypoxemic respiratory failure: management of oxygenation. $J$ Intensive Care Med 19: 140-153, 2004.

RANIERI VM, RUBENFELD GD, THOMPSON BT, FERGUSON ND, CALDWELL E, FAN E, CAMPOROTA L, SLUTSKY AS: Acute respiratory distress syndrome: the Berlin definition. JAMA 307: 2526-2533, 2012.

RONCHI CF, FIORETTO JR, FERREIRA AL, BERCHIERI-RONCHI CB, CORREA CR, KUROKAWA CS, CARPI MF, MORAES MA, YEUM KJ: Biomarkers for oxidative stress in acute lung injury induced in rabbits submitted to different strategies of mechanical ventilation. J Appl Physiol 112: 1184-1190, 2012.

TAKANO K, YAMAMOTO S, TOMITA K, TAKASHINA M, YOKOO H, MATSUDA N, TAKANO Y, HATTORI Y: Successful treatment of acute lung injury with pitavastatin in septic mice: potential role of glucocorticoid receptor expression in alveolar macrophages. J Pharmacol Exp Ther 336: 381-390, 2011.

WANG SG, GUO GH, FU ZH, ZHOU SF: Comparison of conventional mandatory ventilation and high frequency oscillatory ventilation for treatment of acute lung injury induced by steam inhalation injury. Burns 32: 951-956, 2006.

WARE LB, MATTHAY MA: The acute respiratory distress syndrome. $N$ Engl J Med 342: 1334-1349, 2000.

YADAV H, THOMPSON BT, GAJIC O: Fifty years of research in ARDS. Is acute respiratory distress syndrome a preventable disease? Am J Respir Crit Care Med 195: 725-736, 2017. 